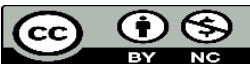

Licenciado sob uma licença Creative Commons

ISSN 2175-6058

http://dx.doi.org/10.18759/rdgf.v19i3.1631

\title{
PODE O “JUIZ NATURAL” SER UMA MÁQUINA?
}

\author{
CAN THE "NATURAL JUDGE” BE A MACHINE?
}

\author{
João Paulo Kulczynski Forster \\ Daniella Bitencourt \\ José Eduardo A. Previdelli
}

\section{RESUMO}

Do direito fundamental ao processo justo, irradiam-se diversos direitos fundamentais processuais, como o do juiz natural. A análise da figura do julgador a partir deste direito processual, assim como o próprio direito, suporta influência da Revolução 4.0, cuja característica marcante é entranhar-se em todos os poros da sociedade. As inovações tecnológicas que começam a se apresentar no panorama mundial possuem profundos impactos na atuação judicial de advogados e juízes. A pesquisa cinge-se ao impacto desta revolução no campo do direito, mais especificadamente no direito processual, em relação à figura do julgador. 0 artigo foi elaborado segundo o método indutivo buscando os limites impostos pelo direito fundamental ao juiz natural à utilização de robôs na atividade jurisdicional. 0 estudo possibilita aferir que, apesar da tecnologia apresentar ferramentas de auxílio à atividade jurisdicional, o direito ao juiz natural impõe limitações à adoção da figura do juiz-robô.

Palavras-chave: Juiz natural. Tecnologia. Juiz-robô.

\section{ABSTRACT}

From the fundamental right to the due process of law, diverse procedural fundamental rights arise, such as the natural judge. The analysis of the figure of the judge from this procedural right, as well as the law itself, undergoes the 
influence of the 4.0 Revolution, whose striking feature is to penetrate in every pore of society. The technological innovations that are beginning to present themselves in the global perspective have profound impacts on the judicial activity of lawyers and judges. The research limits itself to the impact of such revolution in the field of law, more specifically in procedural law, in relation to the figure of the judge. The article was elaborated according to the inductive method, searching for the limits imposed, by the fundamental right to the natural judge, to the use of robots in the jurisdictional activity. The study enables the conclusion that, although the technology presents tools to aid the jurisdictional activity, the right to the natural judge imposes limitations to the adoption of the figure of the robot-judge.

Keywords: Natural judge. Technology. Robot judge.

\section{INTRODUÇÃO}

O termo "crise", para o Direito, tornou-se um clichê nos últimos anos. As mais variadas áreas do Direito estão em crise e este ramo antigo da ciência humana, como bem se definiu no Iluminismo, começa a se deparar com uma realidade que se apresentou há muito mais tempo em outras áreas. A automatização jurídica é realidade. Máquinas - bem entendido, programas, aplicativos - começam a substituir funções outrora exclusivamente humanas. Na área contratual, já se faz uso de robôs para revisão de termos contratuais; há aplicativos que processam indenizações relacionadas a problemas com companhias aéreas. Mais recentemente, 0 Judiciário começou a fazer uso dessas ferramentas tecnológicas.

0 advento do processo eletrônico no Brasil apresentou solução relevante para a superação das denominadas "etapas mortas" do processo, imprimindo celeridade a feitos antes prejudicados pela falta de pessoal em cartórios judiciais. Todavia, as maiores mudanças ainda estão por serem apresentadas. 0 robô ${ }^{1}$ VICTOR, em atuação no Supremo Tribunal Federal desde maio de 2018, tem por objetivo 'ler' todos os recursos extraordinários que chegam à Corte, vinculando-os a determinados temas de repercussão geral. Seria possível afirmar que tal função seria melhor executada por seres humanos? Sabe-se que tarefas repetitivas podem ser exaustivas, atraindo o "erro humano". Tendo o STF 
recebido mais de quarenta e dois mil recursos apenas no ano de 2017, não resta dúvida da utilidade da ferramenta.

Contudo, o próprio Supremo Tribunal Federal (2018) noticia que VICTOR "não se limitará ao seu objetivo inicial", enquanto se afirma, simultaneamente, que a "máquina não decide, não julga, isso é atividade humana". Até quando? Os limites para tanto devem ser pensados e propostos.

0 trabalho encontra-se dividido em três partes. Inicialmente, apresentamos os fundamentos do Direito Humano processual ao juiz natural, com lastro nas previsões estabelecidos em Pactos Internacionais de Direitos Humanos, bem como Constituições nacionais. Em seguida, analisamos a chamada revolução 4.0 e alguns dos seus reflexos na atividade jurídica. Finalmente, tomando por base os fundamentos lançados, examinamos a possibilidade do uso de 'juízes-robôs' sem que ocorra violação do Direito Humano processual antes analisado.

0 estudo foi elaborado por meio da revisão da bibliografia nacional e estrangeira sobre a matéria, utilizando-se, essencialmente, o método indutivo com a finalidade de confirmar a hipótese lançada de possibilidade da atividade jurisdicional ser prestada, ao menos em parte, por robôs, mas nunca em sua totalidade.

\section{DIREITO FUNDAMENTAL AO JUIZ NATURAL}

O processo é pautado substancialmente pela deferência ao direito fundamental ao processo justo (que, em algumas acepções, pode ser visto como devido processo legal dependendo da origem que se estude o termo), cuja origem assenta-se na previsão de respeito à law of the land, prevista no artigo 39 da Magna Charta Libertatum. Tal previsão é entendida como sinônimo de due process of law (CAMBI, 2001), ainda que a expressão somente tenha sido adotada em 1354, quando da edição do Statute of Westminster of the Liberties of London. (DIAS, 2008).

No plano dos Pactos Internacionais de Direitos Humanos (REICHELT, 2016 e MITIDIERO, 2011), o processo justo emerge, dentre outras, das garantias judiciais estabelecidas no artigo 8o da Convenção Americana 
sobre Direitos Humanos e no artigo 6ำ da Convenção Europeia dos Direitos do Homem. Nos planos constitucionais, este direito fundamental encontra previsão, por exemplo, no artigo 5ํㅡㄹ inciso LIV, da Constituição Federal de 1988 sob a indicação de que "ninguém será privado da liberdade ou de seus bens sem o devido processo legal", bem como no artigo 111 da Constituição italiana, estabelecendo que "a jurisdição atuase mediante o justo processo regulado pela lei".

Sem desconhecer a problemática por detrás da adoção da expressão devido processo legal (REICHELT, 2016) ou devido processo legal (ÁVILA, 2008), o conteúdo deste Direito Fundamental resulta em dupla conformação no processo: a primeira delas relacionada à efetiva colaboração, da qual emerge exemplificativamente o disposto no artigo 60 do Código de Processo Civil brasileiro de que "todos os sujeitos do processo devem cooperar entre si para que se obtenha, em tempo razoável, decisão de mérito justa e efetiva". A segunda conformação relaciona-se à constituição do processo atendendo aos direitos fundamentais processuais da igualdade, contraditório, defesa, prova, etc., perante um juiz natural. (MITIDIERO, 2011).

Sob tal contexto, dentre os direitos fundamentais integrantes do feixe que compõem o processo justo, emerge com especial relevância o direito fundamental ao juiz natural, eixo central do presente estudo.

Segundo Ada Pellegrini Grinover (1983, p. 28), este direito se densifica em dupla garantia: a primeira delas consiste na proibição de instituição de juízos extraordinários ex post facto; a segunda, na vedação de afastamento do juízo previamente instituído por lei. Essas garantias são observadas, respectivamente, nas previsões constantes no artigo 5ำ da Constituição Federal brasileira de que "não haverá juízo ou tribunal de exceção" (inciso XXXVII) e de que "ninguém será processado nem sentenciado senão pela autoridade competente" (inciso LIII). (GOMES, 1994).

Observado o direito comparado, a Constituição Italiana assegura o direito subjetivo dos indivíduos (ROMBOLI, 1981) de que "ninguém pode ser privado do juiz natural designado por lei" (artigo 25), ainda que não indique o conteúdo ou alcance de desta garantia. Este dispositivo apresenta dois conceitos distintos, mas complementares: o de juiz natural 
e o de juiz pré-constituído por lei (CUNHA, 2006). Para Roberto Romboli (1981, p. 127):

La Costituzione tutela la purezza e la regolarità dell'attività giurisdizionale garantendo l'indipendenza e l'imparzialità del giudice e mentre la prima riguarda l'ufficio, l'organo giudicante oggettivamente inteso, la seconda prende invece in considerazione il giudice nel momento del concreto esercizio dela funzione giurisdizionale.

0 direito fundamental ao juiz natural é observado no artigo $8^{\circ}$ da Convenção Americana sobre Direitos Humanos, sob a garantia judicial de ser ouvido "por um juiz ou tribunal competente, independente e imparcial, estabelecido anteriormente por lei". No mesmo sentido, a Convenção Europeia, assegura a qualquer pessoa, "que a sua causa seja examinada [...] por um tribunal independente e imparcial, estabelecido pela lei" (artigo 6음.

O direito fundamental ao juiz natural, pode ser compreendido como a previsão de um juiz "imparcial, competente e não designado premeditadamente para o julgamento” (TEIXEIRA, 2016, p. 189). Ou seja, para que seja concretizado tal direito, exige-se a aferição de um órgão julgador que goze das qualidades de imparcialidade, competência e aleatoriedade (MARINONI; MITIDIERO, 2012).

A imparcialidade, elemento integrante do conceito de jurisdição (CAPPELLETTI, 1999) e conditio sine qua non do juiz (BADARÓ, 2015) diz respeito ao elemento anímico do órgão julgador: não há qualquer interesse no resultado do processo judicial, como forma de preservação do tratamento isonômico das partes (MARINONI; MITIDIERO, 2012). 0 predicado em questão enseja as vedações aos juízes, previstas no artigo 95, parágrafo único da Constituição Federal brasileira, bem como ensejam a arguição - pelo próprio juiz ou pelos demais atores processuais - de impedimento (artigo 144, CPC/15) e suspeição (artigo 145, CPC/15) do órgão julgador. No mesmo sentido, a Constituição italiana, em seu artigo 111, estabelece o desenvolvimento do processo "no contraditório entre as partes, em condições de igualdade perante juiz terceiro e imparcial".

Outra consequência diz respeito à competência, cujos critérios devem estar "abstrata e genericamente predeterminados em lei" (CUNHA, 
2006, p. 502), relacionando-se à previsão constitucional anterior ao ajuizamento da demanda (MARINONI; MITIDIERO, 2012) de qual órgão julgador é competente para a apreciação da questão litigiosa. A prévia disposição legal deve incluir, ainda "os critérios de nomeação para aquela vara ou órgão fracionário do tribunal, bem como os critérios de substituição" (BADARÓ, 2015). Esta esfera do juiz natural não possui o condão de proibir "a instituição de juízos especializados, préconstituídos e pertencentes ao Poder Judiciário” (VASCONCELOS, 2000, p. 12), considerando que a própria Constituição Federal prevê juízos especializados em determinadas matérias (CUNHA, 2006), reforçando-se a sua instituição prévia aos fatos objetos do julgamento.

Por fim, a aleatoriedade está ligada à forma de distribuição dos processos e recursos, de forma que não haja qualquer direcionamento do processo a determinado julgador, ou sob outro viés, seja afastada a possibilidade de que este determinado julgador atue no processo. Conforme Leonardo Cunha (2006, p. 506), "as regas de distribuição concretizam a aplicação do juiz natural”, importando sua violação a situação em que o juiz foi "deliberadamente escolhido pela parte" (MARINONI; MITIDIERO, 2012, p. 645).

Sob tal aspecto, para que seja assegurado o Direito Fundamental ao juiz natural, exige-se a apresentação conjunta destes três fatores imparcialidade, competência e aleatoriedade - traduzindo "uma das mais fundamentais conquistas do processo moderno" (GOMES, 1994, p. 418). Verifica-se, portanto, tratar-se de efetivo Direito Humano e Fundamental das partes no processo, de modo que sua visão tradicionalmente era voltada para o processo "tradicional", não contemplando todas as consequências apresentadas pela tecnologia no mundo moderno. 0 direito vem de ser atingido tardiamente pela imensa massa de inovações tecnológicas, que merecem detido exame quando relacionadas à garantia apresentada. 


\section{A REVOLUÇÃO 4.0 E ALGUNS DOS SEUS REFLEXOS NO DIREITO}

A complexidade do tema merece profunda análise, muito mais do que simples abordagem acrítica ou ainda o entusiasmo pelas benesses trazidas pela tecnologia (LORENZETTI, 2004). Vivencia-se, hoje, o que os especialistas e estudiosos denominaram de a Revolução 4.0 ou a Quarta Revolução Industrial (SCHWAB, 2016). Segundo Schwab (2016), as modificações serão cada vez maiores, mais intensas e profundas com o passar do tempo. No mercado de trabalho, por exemplo, ao menos a curto prazo, o impacto será negativo, diante de sistemas inteiros que serão modificados, pois as novas tecnologias mudarão drasticamente a natureza do trabalho em todos os setores e ocupações (SCHWAB, 2016). O mesmo autor (2016) esclarece que, apesar deste panorama inicialmente parecer devastador (com desemprego em massa), as habilidades dos seres humanos serão realocadas para outros lugares. Trata-se do denominado "efeito capitalizador", em que as demandas por novos bens e serviços aumentam e conduzem a invenção de novas profissões, empresas e até mesmo indústrias.

Preston (2015 apud Goodwin), em relação à nova era, afirma:

A Uber, a maior empresa de táxis do mundo, não possui veículos. 0 Facebook, o proprietário de mídia mais popular do mundo, não cria conteúdo. Alibaba, o varejista mais valioso, não tem estoque. E o Airbnb, o maior provedor de hospedagem do mundo, não possui imóveis. Algo interessante está acontecendo.

A ideia de uma revolução no mercado de trabalho, por óbvio, não é sem precedentes na história. Em outras épocas, a sociedade também sofreu mudanças radicais, rápidas e contundentes, tendo a revolução Industrial como um bom exemplo (FINKELSTEIN, 2011). Parece bastante claro hoje que, se o homem não estava pronto para reconhecer a totalidade das mudanças que a Revolução Industrial traria, a história se repete (FINKELSTEIN, 2011). A Quarta Revolução Industrial possui efeitos vastos e consequências evidentes: desde a operacionalização de toda a vida política até à facilitação da vida social, os números confirmam 
as assertivas: até 2012 o número de usuários de computadores chegará a dois bilhões; 70\% das pessoas consideram a internet indispensável e existem cerca de 220 milhões de domínios (MOREIRA, 2012). Trata-se de um caminho sem volta.

Nada obstante, é preciso lembrar que os avanços científicos e tecnológicos só fazem jus a esse vocábulo se puderem proporcionar à humanidade mais dignidade e melhores condições de vida. (ROVER, 2004). Neste sentido, espera-se que Schwab tenha razão: após esse período de transição, o ser humano deve conseguir se reinventar para uma efetiva implementação dos Direitos Humanos.

Assim, a era 4.0 resulta da soma de dois elementos principais: a tecnologia e a velocidade. Um dos aspectos que mais identificam a Revolução 4.0 é a sua capacidade de estabelecer a ligação entre máquinas, dispositivos, sistemas e pessoas, todos unidos a uma inteligência artificial que faz tudo acontecer (TSURU, 2018). A perspectiva de mundo está sendo totalmente alterada, desde os crimes (digitais), as profissões como as conhecemos, bem como os litígios e, inevitavelmente, também a figura do julgador - ainda que essa realidade tenha demorado a lançar sua sombra sobre o Judiciário.

O desenvolvimento tecnológico estabelece novas relações sociais e, assim, igualmente projeta consequências para o Direito. 0 Judiciário está utilizando programas bastante sofisticados de modo a contribuir com o aumento da celeridade e confiabilidade (CORRÊA, 2010). Portanto, convém estabelecer novas referências que se distanciem e se reinventem juridicamente, o que tradicionalmente não mais é usual, prático, rápido, inovador, isto é, o direito também está ingressando na Quarta Revolução Industrial, no seu próprio tempo. Imagine-se que houve um tempo em que o uso de cartões eletrônicos (uma parceria com a IBM) ajudou a organizar o trabalho em uma seção judiciária na Pensilvânia, EUA, com grande impacto na celeridade processual - na década de 60! (ELLENBONGEN, 1964). A “automação" dos tribunais foi recebida com grande entusiasmo, sem que se pudesse imaginar que esse tipo de atividade se tornaria absolutamente trivial e completamente indispensável. As alterações que estão por vir são colossais quando comparadas à esta. 
Greco e Martins (2001, p. 15) melhor explicam: "se a revolução econômica e tecnológica é inegável, cabe ao jurista acompanhá-la, revendo até as premissas de sua dogmática, reconhecendo as mudanças que estão ocorrendo com a globalização". As condições que devem guiar as decisões é um novo critério de racionalidade afinado com as características de um padrão normativo, a ponto de se questionar se será possível a utilização de um juiz robô, uma inteligência artificial capaz de julgar ao menos as questões denominadas "em massa". A racionalidade exigirá um conceito que seja ao mesmo tempo "procedural e sensível aos aspectos normativos dos fenômenos sobre os quais irá ser aplicado". Sendo possível identificar uma estrutura comum aos padrões de decisão, o ajustamento perderia em aparência de solução ad hoc, porém ganharia em razoabilidade. (GRECO; MARTINS, 2001).

A revolução tecnológica é um dos elementos mais marcantes dos novos tempos: a fragilidade das tradições e a reformulação das estruturas e relações sociais são constantes e velozes, causando o sentimento de insegurança e ansiedade. Este processo atual refere-se às tecnologias de informação, processamento e comunicação. Como todas as outras mutações tecnológicas com caráter de revolução, sua característica essencial é a penetração em todos os setores da vida humana, tal como são entendidas ou concebidas hoje. (SOUZA, 2014). Destarte, observa-se que todos os direitos ganham ou ganharão novos contornos: o debate no quanto a Revolução 4.0 irá influenciar o julgador e por consequência o direito dos litigantes possui extrema relevância. Diuturnamente a sociedade se depara com novos desafios trazidos pela revolução e paralelamente as celeumas em torno das garantias individuais. (LONGHI, 2017).

A sociedade e, em especial, o sistema jurídico como arquitetado demonstra fragilidade majorada a cada "novo gadget (v.g. smartphone, tablet, mp3 player, etc), software (v.g. os sistemas operacionais) ou hardware (v.g. notebooks) lançados pelas empresas de tecnologias" (MOREIRA, 2012, p. 14). Particularmente, acredita-se que a Revolução 4.0, muito além da "singela" transformação tecnológica, trará verdadeira modificação cultural. Por conseguinte, torna-se necessário repensar as estruturas jurídicas. Faz-se necessário um novo olhar, com novos parâmetros temporais, de descentralização, com atenção à democracia 
participativa, de administração mais transparente e eficaz com custos mínimos do Estado-gestor (BASTOS; RAIMUNDI, 2011).

\section{O USO DE JUÍZES ROBÔS}

Santiago Sentís Melendo (1974, p. 11), com grande clareza, pontuou: "Encomendar a um homem a tremenda missão de julgar, e depois dizer-lhe como deve julgar, parece um paradoxo ou um sarcasmo; não é mecanizá-lo, ou automatizá-lo; é algo pior: é desumanizá-lo". Não suspeitava, à época, que eventual desumanização da função judicial não se daria (apenas) por conta da sobrecarga laboral, mas por singela substituição do homem pela máquina. Não se chegou nesse ponto ainda, é verdade. Mas a indagação é esta: é possível chegar lá? Há alguma barreira legal ao emprego de juízes-robôs?

Não se trata de ficção científica, nem de realidade estrangeira. Além do robô VICTOR, em plena atividade no Supremo Tribunal Federal, o Tribunal de Justiça do Estado de Minas Gerais utiliza o sistema "Radar", que permitiu o julgamento de 280 processos em uma sessão que durou poucos segundos em novembro de 2018 (TJMG, 2018). Entidades de advogados começam a protestar contra o uso de robôs que, em tese, prestam serviços privativos à advocacia (CONJUR, 2018). 0 cenário está posto e, assim como em diferentes momentos de inovação, cabe a consideração dos limites dessa utilização.

Nos Estados Unidos, a automação da advocacia é uma realidade bem presente. Estudo recente demonstrou a incomparável eficiência no uso de robôs: na fase pretrial, as partes têm se valido do electronic document discovery (e-discovery), sendo que um discovery "tradicional", realizado com 6 milhões de documentos, em 1978, custou às partes o valor de 2,2 milhões de dólares. Mais recentemente, programas foram empregados para examinar 1,5 milhão de documentos ao preço de cem mil dólares uma fração do custo original. (DALKE, 2013). Há exemplos mundiais do uso de ferramentas eletrônicas para mediação, mas a "fronteira final", como refere Dalke, parece ser o julgamento por robôs. 0 autor (DALKE, 
2013) bem percebe que o tema da independência judicial é curial em se tratando de julgamentos por robôs.

A imparcialidade, que tem por pressuposto a independência judicial, revela-se como "conditio sine qua non de todo o Estado de Direito" (DIAS, 2005, p. 72), não está, neste momento, assegurado. Trata-se, aqui, não de garantia única do próprio juiz, mas de uma garantia dos cidadãos ${ }^{2}$. Constatando que os julgadores, em regra, desconhecem linguagem de programação ou simplesmente não tenham formação na área, quem seria o responsável pelo desenho e arquitetura do sistema? Veja-se que essa questão não é nenhum pouco problemática quando se fala do processo eletrônico, pois o regramento processual aplicável está integralmente pré-constituído, e regra tão somente o procedimento, nunca o resultado. A estruturação de um código criador de um "robô" apto a proferir julgamentos dependeria do trabalho de muitas pessoas. Mas, ao fim e ao cabo, alguém teria de fornecer respostas ao autômato. Seria como se uma ampla gama de casos tivesse um único juiz - o que acabaria por solapar o critério de aleatoriedade do magistrado encarregado de julgar uma determinada demanda.

O realismo jurídico - ou ceticismo construtivo, como prefere Jerome Frank (BRUTAU, 1977) - seguramente teria algo a dizer a tal respeito. 0 "movimento" que mais levou em conta a subjetividade das decisões judiciais não projetava o advento de máquinas julgadoras, e seguramente as repeliria. Uma das passagens mais instigantes de Holmes, afirmaram posteriormente os ditos "realistas", é a inicial de seu livro The Common Law: "The life of the law has not been logic: it has been experience" (FISHER, 1993, p. 9). Dizia, em seguida, que até mesmo os preconceitos compartilhados pelos juízes com o resto da humanidade, têm conexão muito maior do que o silogismo na determinação das regras que governam os homens. A necessária humanidade da função judicial não pode, jamais, ser suplantada desse ofício. 0 uso de juízes-robôs seria a algoritmização do direito alçada ao seu nível máximo.

Para o presente estudo, a maior barreira que se desenha, em matéria de julgamentos automatizados ou "robóticos", é a do juiz natural. Observase que mesmo considerações recentes acerca deste Direito Fundamental Processual não levam em conta a automação judicial levada ao extremo. 
A humanidade da função judicial é absolutamente desejável, assim como os sentimentos - responsáveis (LAGIER, 2009) - que os juízes possuem.

Mas, afinal, por que a manutenção do caráter humano da atividade judicial seria tão cara aos jurisdicionados? Parece evidente que demandas de massa poderiam ser muito beneficiadas pelo emprego de juízes-robô. Não resta dúvida que a filtragem de informações poderia ser feita por máquinas - a exemplo do desempenho de VICTOR no Supremo Tribunal Federal. Mas, não o julgamento propriamente dito. Pode-se perceber que as decisões no Direito, como referiu Justice Marshall no julgamento United States v. Kras (409 U.S. 434, 460 - 1973), "frequentemente não têm nenhuma relação com a compreensão das experiências humanas, afeto, sofrimento - de como as pessoas vivem" (HENDERSON, 1987).

Ainda que essa consideração seja fria, sabe-se que as decisões devem se ater a elementos racionais e não meramente subjetivos. Por outro lado, Lynne Henderson (1987) recorda que, no julgamento Brown v. Board of Education, a defesa do Estado de Kansas argumentou que "como a estrutura física das escolas era igual, isso encerrava a questão sobre o Direito. A reação psicológica à segregação é algo separado dos elementos objetivos do sistema escolar". Desnecessário elaborar o quão falsamente lógico é o mencionado argumento, revelando que o elemento da empatia pode levar a importantes superações de entendimentos estabelecidos no âmbito do Poder Judiciário - o que seguramente não está ao alcance de nenhuma máquina (hoje). Sabe-se que a evolução digital é acelerada e elementos como o machine learning podem mudar a situação rapidamente, em face da tecnologia disponível para (muito) breve (COGLIANESE, LEHR, 2017).

Há situações, portanto, em que a presença do ser humano é indispensável. Pesquisas indicam que as pessoas aceitariam robôs para o desempenho de algumas funções ancilares, mas as recusam em substituição a situações tipicamente humanas - como um amigo, por exemplo (DAUTENHAHN; WOODS; KAOURI; WALTERS; KOAY; WERRY, 2005). Ainda que a pesquisa mencionada não apresente tal conclusão, dificilmente as pessoas aceitariam um autômato como magistrado.

Mais do que simplesmente uma questão empática, a automação pode, sim, trazer riscos. Sistemas de inteligência artificial que permitam o 
aprimoramento (auto aprendizado) dos robôs são cada vez mais comuns e são dignos de atenção diferenciada. Experiência recente da empresa Facebook levou ao desligamento de dois robôs que foram projetados para conversar entre si. A decisão ocorreu após as máquinas terem desenvolvido uma linguagem própria (e supostamente mais eficiente) para se comunicarem, sem que os programadores que os "controlavam" pudessem compreender o que estava sendo "falado" (GRIFFIN, 2017).

Nem todos os aspectos dessa automação são necessariamente negativos. 0 trabalho desempenhado pelo sistema VICTOR até o momento tem sido de grande valia. A identificação e reunião de processos idênticos - ou, ao menos, com o mesmo conteúdo de causa de pedir e pedido encontra lastro no art. 926 do CPC/15, já que a automação pode ajudar os tribunais a uniformizarem sua jurisprudência e mantê-la estável, íntegra e coerente. Aponta-se, aqui, a relevância do direito fundamental à igualdade processual, em sua percepção enquanto igualdade pelo processo, como bem pontua Rafael Abreu (2015). Na esteira do pensamento do aludido autor, oferecer "tratamento diverso em casos iguais, sem as devidas diferenças relevantes, significa vulnerar frontalmente a igualdade, da mesma forma com que será afrontada no caso de aplicação do precedente sem consideração das diferenças substanciais do caso" (ABREU, 2015, p. 193). Não se vislumbra, ainda, conflito entre igualdade e o juiz natural. 0 tema da automação ainda carece de maior aprofundamento para que, com as evoluções necessárias, siga sendo o juiz natural uma barreira.

\section{CONSIDERAÇÕES FINAIS}

A compreensão da atividade e uso de robôs no Poder Judiciário afetando diversas carreiras jurídicas, não apenas a de magistrado - não pode soar como uma regressão ao ludismo. As máquinas podem, sim, desempenhar funções relevantes e auxiliar no sistema judicial. 0 uso irrestrito desses robôs encontra barreiras legais, como a do juiz natural. Em suas origens, a garantia, galgada a Direito Fundamental, não fora projetada com tamanho alcance. Mas ela o possui, pois a ideia de natureza repele tudo aquilo que é artificial, excepcional. Na atividade jurisdicional, 
não diferente, a humanidade e seus consequentes sentimentos são predicados desejáveis aos julgadores.

Não se acha presente, neste momento, a tecnologia para que haja uma simples substituição do juiz pelo "robô". A barreira é, portanto, além de legal, igualmente tecnológica. A complexidade do ato decisório reclama o desenvolvimento de programação de altíssima complexidade, afinal, existem motivos pelos quais os médicos também não foram simplesmente substituídos por máquinas possivelmente de maior precisão. Da mesma forma, não se pode ignorar a própria restrição das pessoas ao desempenho de atividades e situações tipicamente humanas por máquinas. Revela-se altamente provável que não as agradasse a figura de um julgador desprovido de sentimentos.

Imaginando possível a superação dos limites emocionais ou tecnológicos envolvidos, a barreira legal ainda se apresenta. A inovação apresentada pela revolução digital frequentemente encontra fronteiras éticas intransponíveis. Apresenta-se, na utilização de juízes-robôs, a amarra do Direito Fundamental ao juiz natural que implica a necessidade de um julgador humano. 0 robô é um julgador, para o presente momento, de exceção, afrontando o disposto no art. 5º , XXXVII, CF. Toda a estrutura da Lei Orgânica da Magistratura e da carreira judicial nacional, conforme preconizada pela Carta Magna, apresentam à sociedade um juiz de carne e osso e, no caso brasileiro, devidamente concursado ou com ingresso na carreira pelo quinto constitucional.

Outra consideração é de que o elemento da imparcialidade, cujo pressuposto é a independência. A máquina ou programa depende do homem que a projeta. A tecnologia e a velocidade apresentadas pela Revolução 4.0 não podem se sobrepor às garantias fundamentais dos cidadãos. Sistemas de inteligência artificial que permitam o aprimoramento (auto aprendizado) dos robôs também apresentam seu lado perigoso, diante da possibilidade de estes escaparem do controle de seus criadores ou utilizadores.

Esse tipo de experimento deve reduzir a empolgação com uso das ferramentas eletrônicas na atividade judicial, incrementando a cautela e a razoabilidade no seu desenvolvimento e uso. Por isso, a figura do juiz natural, efetivamente humano, se revela tão importante neste 
momento histórico. Enquanto não houver uma política legislativa clara, aberta, democraticamente debatida, o uso desses instrumentos deve, necessariamente, ficar relegado a tarefas de segundo plano e sempre sujeitas à revisão e questionamento humanos. Toda a preocupação que circunda a subjetividade da decisão judicial é geometricamente ampliada quando se relega a um autômato o julgamento, pois se coloca em xeque a independência e a imparcialidade que são tão caras ao ato de julgar.

Sabe-se que a igualdade pelo processo, apresentada ao final do texto, encontra profundo lastro na segurança jurídica. 0 tratamento distinto de casos iguais é insustentável sob qualquer perspectiva no Estado Democrático de Direito. A automação seguramente pode auxiliar nesse aspecto, desde que não suplante por inteiro a figura do julgador humano, e não apenas no momento pré-processual (durante a programação do "robô"), mas também durante e após o processo, para o seu controle.

Uma provocação justificada é o reclamo ao princípio da eficiência administrativa. A máquina não faria mais por menos? Não haveria um menor dispêndio de recursos públicos se ao menos alguns tipos de processos fossem julgados por máquinas? Os advogados, em certa medida e em algumas áreas, já estão sendo substituídos. Os juízes os seguirão assim como promotores, peritos e demais auxiliares do Judiciário - se não forem colocados limites. 0 juiz natural é apenas um deles, sob pena da pergunta de Jerome Frank - Os juízes são humanos? - ser respondida negativamente.

\section{NOTAS}

10 termo 'robô' é usado, ao longo desse artigo, como uma referência única a programas ou ferramentas tecnológicas de qualquer sorte que substituam funções humanas.

2 O Tribunal Constitucional de Portugal, no Acórdão 135/88, emitiu orientação nesse sentido: "A independência do juiz é, acima de tudo, um dever - um dever ético-social. A independência vocacional, ou seja, a decisão de cada juiz de, ao dizer o Direito, o fazer sempre esforçando por se manter alheio - e acima de influências exteriores é, assim, o seu punctum saliens. A independência, nessa perspectiva, é, sobretudo, uma responsabilidade". PORTUGAL. Tribunal Constitucional. 2a․ Seção. Proc. n. 137/87. Relator Conselheiro Messias Bento. 


\section{REFERÊNCIAS}

ABREU, Rafael Sirangelo de. Igualdade e processo: posições processuais equilibradas e unidade do direito. São Paulo: Ed. RT, 2015.

ÁVILA, Humberto. O que é «devido processo legal»? Revista de Processo, São Paulo, v. 163, p.50-59, set. 2008.

BADARÓ, Gustavo Henrique Righi Ivahy. Juiz natural e inamovibilidade. Revista Brasileira de Ciências Criminais, São Paulo, v. 114, p.501-536, maio/jun. 2015. Disponível em: http://www.mpsp.mp.br/ portal/page/portal/documentacao_e_divulgacao/doc_biblioteca/bibli_ servicos_produtos/bibli_boletim/bibli_bol_2006/RBCCrim_n.114.15.PDF. Acesso em: 15 nov. 2018.

BASTOS, José Umberto Braccini; RAIMUNDI, Fábio. Fiscalização na Era Digital - novos paradigmas para o direito tributário. In: MARQUES, Jader; SILVA, Maurício Faria (Orgs.). 0 Direito na Era Digital. Porto Alegre: Livraria do Advogado, 2012, p. 95-111.

BRASIL. Supremo Tribunal Federal (STF), notícias. Inteligência Artificial vai agilizar a tramitação de processos no STF. Brasília, 30 de maio de 2018. Disponível em: http://www.stf.jus.br/portal/cms/verNoticiaDetalhe. asp?idConteudo=380038> . Acesso em: 23 nov. 2018.

Tribunal de Justiça de Minas Gerais (TJMG), notícias. TJMG utiliza inteligência artificial em julgamento virtual. Minas Gerais, 07 de novembro de 2018. Disponível em: http://www.tjmg.jus.br/portal-tjmg/noticias/ tjmg-utiliza-inteligencia-artificial-em-julgamento-virtual.htm\#.W_fauuhKjIV. Acesso em: 23 nov. 2018.

BRUTAU, José Puig. A jurisprudência como fonte de direito. Porto Alegre: AJURIS, 1977.

CAMBI, Eduardo. Direito constitucional à prova no processo civil. São Paulo: Revista dos Tribunais, 2001.

CAPPELLETTI, Mauro. Juízes legisladores? Tradução de Carlos Alberto Alvaro de Oliveira. Porto Alegre: Sérgio Fabris Editor, 1999.

COGLIANESE, Cary; LEHR, David. Regulating by Robot: Administrative Decision Making in the Machine-Learning Era. Penn Law: legal Scholarship 
Repository. Pensilvânia, jun. 2005. Disponível em: https://scholarship.law. upenn.edu/faculty_scholarship/1734/. Acesso em: 16 nov. 2018.

CONSELHO DA EUROPA. Convenção Europeia dos Direitos do Homem, de 4 de novembro de 1950. Disponível em: http://www.echr.coe.int/Documents/ Convention_POR.pdf. Acesso em: 16 nov. 2018.

CONSULTOR JURÍDICO (CONJUR). Entidades de advogados reagem a robô que ajuda em ações trabalhistas. 1 de julho de 2018. Disponível em: https://www. conjur.com.br/2018-jul-01/entidades-advogados-reagem-robo-ajuda-acoestrabalhistas. Acesso em: 23 nov. 2018.

CORRÊA, Gustavo Testa. Aspectos Jurídicos da Internet. 5a Edição. São Paulo: Saraiva, 2010.

CUNHA, Leonardo José Carneiro da. Anotações sobre a garantia constitucional do juiz natural. In: FUX, Luiz; NERY JÚNIOR, Nelson; ALVIM, Teresa Arruda (Org.). Processo e Constituição: estudos em homenagem ao professor José Carlos Barbosa Moreira. São Paulo: Revista dos Tribunais, 2006.

DALKE, Dean. Can Computers Replace Lawyers, Mediators and Judges? The Advocate, Vancouver, v. 703, set. 2013. Disponível em: http://www.theadvocate.ca/. Acesso em: 23 de nov. 2018.

DAUTENHAHN, Kerstin; WOODS, Sian; KAOURI, Christina; WALTERS, Michael Leonard; KOAY, Kheng Lee; WERRY, Iain P. What is a robot companion - friend, assistant or butler? IEEE/RSJ International Conference on Intelligent

Robots and Systems. Canadá, 2005. Disponível em: https://ieeexplore.ieee. org/document/1545189. Acesso em: 23 de nov. 2018.

DIAS, Jefferson Aparecido. Princípio do devido processo legal. In: OLIVEIRA NETO, Olavo de; LOPES, Maria Elizabeth de Castro (Org.). Princípios processuais civis na constituição. Rio de Janeiro: Elsevier, 2008. p. 25-46.

DIAS, Nélia Daniel. A responsabilidade civil do juiz. 2. ed. Lisboa: DisLivro, 2005.

ELLENBONGEN, Henry. Automation in the Courts. American Bar Association Journal, Vol. 50, No. 7, p. 655-658, jul. 1964.

FINKELSTEIN, Maria Eugênia. Direito do Comércio Eletrônico. $2^{\text {a }}$ Ed. Elsevier: Rio de Janeiro, 2011. 
GOMES, Luiz Flávio. Apontamentos sobre o princípio do Juiz Natural. Revista dos Tribunais, São Paulo, v. 703, p.417-422, maio 1994.

GRECO, Marco Aurelio; MARTINS, Ives Gandra. Direito e Internet: relações jurídicas na sociedade informatizada. Revista dos Tribunais: São Paulo, 2001.

GRIFFIN, Andrew. Facebook's Artificial Intelligence Robots Shut down After they Start Talking to Each Other in their own Language. Independent. London, 2017. Disponível em: https://www.independent.co.uk/life-style/ gadgets-and-tech/news/facebook-artificial-intelligence-ai-chatbot-newlanguage-research-openai-google-a7869706.html. Acesso em: 29 nov. 2018.

GRINOVER, Ada Pellegrini. O princípio do juiz natural e sua dupla garantia. Revista de Processo, São Paulo, v. 29, p.11-33, jan./mar. 1983.

HENDERSON, Lynne. Legality and Empathy. Scholarly Commons @ UNLV Law. Las Vegas, 1986. Disponível em: https://scholars.law.unlv.edu/cgi/ viewcontent.cgi?referer=https://www.google.com.br $/ \&$ httpsredir $=1 \&$ article= 1893\&context=facpub. Acesso em: 29 nov. 2018.

HOLMES, Oliver Wendell. The common law. In: FISHER III, William W.; HORWITZ, Morton J.; REED, Thomas A. (Orgs.). American legal realism. Oxford: Oxford University Press, 1993.

ITALIA. Costituzione Italiana: Edizione in lingua portoghese, de 27 de dezembro de 1947. Roma, Disponível em: https://www.senato.it/application/ xmanager/projects/leg18/file/repository/relazioni/libreria/novita/XVII/ COST_PORTOGHESE.pdf. Acesso em: 16 nov. 2018.

LAGIER, Daniel González. Emociones, responsabilidade y derecho. Madrid: Marcial Pons, 2009.

LONGHI, João Victor Rozatti. Processo Legislativo Interativo. Curitiba: Juruá, 2017.

LORENZETTI, Ricardo L. Comércio Eletrônico. São Paulo: Revista dos Tribunais, 2004.

MARINONI, Luiz Guilherme; MITIDIERO, Daniel. Direitos Fundamentais Processuais. In: SARLET, Ingo Wolfgang; MARINONI, Luiz Guilherme; MITIDIERO, Daniel. Curso de Direito Constitucional. São Paulo: Revista dos Tribunais, 2012. 
MITIDIERO, Daniel. Direito fundamental a um processo justo. Revista Magister de Direito Civil e Processual Civil, Porto Alegre, v. 45, p.22-34, nov./dez. 2011.

MOREIRA, Fábio Lucas. Da "sociedade informática” de Adan Schaff ao estabelecimento dos fundamentos e princípios do marco civil da internet (PL 2.126/2011). In: O Direito na Era Digital. MARQUES, Jader; SILVA, Maurício Faria (Orgs.). Porto Alegre: Livraria do Advogado, 2012.

ORGANIZAÇÃO DOS ESTADOS AMERICANOS. Convenção Americana sobre Direitos Humanos, 22 de novembro de 1969. Disponível em: https://www. cidh.oas.org/basicos/portugues/c.Convencao_Americana.htm. Acesso em: 16 nov. 2018.

PRESTON, Rob. Ruptura Digital não é o que você pensa. Forbes, 20 de abril de 2015. Disponível em: https://www.forbes.com/sites/oracle/2015/04/20/ digital-disruption-its-not-what-you-think/\#20a1b0559e06. Acesso em: 06 nov. 2018.

ROMBOLI, Roberto. Il giudice naturale: Studio sul significato e la portata del principio nell'ordinamento constituzionale italiano. Milano: Giuffrè, 1981.

ROVER, Aires José. Direito e Informática. Manole: Barueri, São Paulo, 2004.

MELENDO, Santiago Sentís. Naturaleza de la prueba: la prueba es libertad. Revista dos Tribunais, São Paulo, v. 63, n. 462, p. 11-22, abr. 1974.

SCHWAB, Klaus. A Quarta Revolução Industrial. São Paulo: Edipro, 2016.

SOUZA, Allan Rocha de. Cultura, Revolução Tecnológica e os direitos autorais. In: Direito Privado e Internet. MARTINS, Guilherme Magalhães (Org.). Atlas: São Paulo, 2014.

TEIXEIRA, Guilherme Puchalski. Direito fundamental à jurisdição (acesso à justiça) e direito ao juiz natural. In: REICHELT, Luis Alberto; DALLALBA, Felipe Camilo (Org.). Primeiras linhas de Direito Processual Civil: Volume 1 Teoria Geral do Processo Civil. Porto Alegre: Livraria do Advogado, 2016.

TSURU, Agência Digital. Indústria 4.0: a Quarta Revolução Industrial já é uma realidade? Blog da Agência Tsuru. 30 de maio de 2018. Disponível em: https://www.agenciatsuru.com.br/blog/industria-4-0-a-quarta-revolucaoindustrial/. Acesso em: 14 nov. 2018. 
VASCONCELOS, Rita de Cássia Corrêa de. Breves anotações sobre o princípio do juiz natural. Verba Iuris, Porto Alegre, p.07-14, ago. 2000.

Recebido em: 23-11-2018

Aprovado em: 18-12-2018

\section{João Paulo Kulczynski Forster}

Doutor em Direito pela UFRGS. Mestre em Direito pela Universidade Federal do Rio Grande do Sul - UFRGS. Pós-graduado em Direito Empresarial com ênfase em Direito Tributário pela Fundação Getúlio Vargas - FGV/RS. Graduação em Ciências Jurídicas e Sociais pela Pontifícia Universidade Católica do Rio Grande do Sul - Professor no Centro Universitário Ritter dos Reis. E-mail: joao_forster@ uniritter.edu.br

\section{Daniella Bitencourt}

Mestranda, bolsista Capes em Direitos Humanos, linha de pesquisa Direitos Humanos, Estado de Direito e Constitucionalismo pela UniRitter (término em 02/2019). Dissertação sobre Orçamento Público na Educação (qualidade, eficiência, IDH e Direitos Humanos). Especialista em Tributos em Espécie pela Universidade Federal do Rio Grande do Sul - UFRGS e Direito Tributário Geral pela Universidade Mackenzie/SP. Graduada pelo Centro Universitário Ritter dos Reis. E-mail: daniellabitencourt4@gmail.com

\section{José Eduardo A. Previdelli}

Mestrando em Direitos Humanos pelo Unirriter (atual). Graduado em Direito pela Universidade Luterana do Brasil. Pós-graduado em Formação Pedagógica de Professores pela FAQI. Pós-graduado em Direito Processual Civil pela Uniritter. Tutor da Escola Superior da Magistratura (2008-atual). Tutor da Escola Superior do Ministério Público. Juiz Leigo do Juizado Especial Cível de Guaíba. Assessor de Juiz e Assessor de Desembargador. E-mail: edprevidelli@gmail.com

Campus FAPA - Av. Manoel Elias, 2001 - Morro Santana - Porto Alegre/RS - CEP 91240-261. 